\title{
Simposio Reforma Constitucional y Derechos Humanos
}



Liliana Galdámez Zelada. Doctora en Derecho por la Universidad de Valladolid y Licenciada en Ciencias Jurídicas y Sociales de la Universidad de Chile. Se desempeña como profesora de Derecho Constitucional en la Facultad de Derecho de la Universidad de Talca y es investigadora del Centro de Estudios Constitucionales de la misma Universidad.

lgaldamez@utalca.cl

Pedro Salazar Ugarte. Licenciado en Derecho y Doctor en Filosofía Política. Es investigador de tiempo completo del Instituto de Investigaciones Jurídicas de la Universidad Nacional Autónoma de México (desde 2003) y profesor de Teoría de la Constitución, Teoría de la Democracia y Derechos Humanos en la Facultad de Derecho de la UNAM. Ha impartido cursos de doctorado, maestría y doctorado en diversas instituciones de educación superior nacionales.

pedsalug@yahoo.com

Humberto Sierra Porto. Abogado de la Universidad Externado de Colombia, especialista en Derecho Constitucional y Ciencias Políticas del Centro de Estudios Constitucionales de Madrid y Doctor en Derecho Constitucional en la Universidad Autónoma de Madrid. Es Presidente de la Corte Interamericana de Derechos Humanos y profesor titular de la Universidad Externado de Colombia y se desempeñó como Magistrado de la Corte Constitucional de Colombia (2004-2007). Es autor de diversas publicaciones en el área de justicia constitucional, fuentes de derecho y derechos fundamentales.

humbertoasierra@gmail.com

Farit Rojas Tudela. Abogado, Máster en Gestión Gubernamental, Máster en Investigación en Ciencias Sociales y Doctor en Epistemología. Ha sido profesor de Teoría del Estado y Derecho Constitucional de la Universidad Católica Boliviana (UCB). Profesor de postgrado en la Universidad Andina Simón Bolívar (La Paz -Bolivia), en la Universidad Santo Tomás (Bogotá -Colombia) y en la Universidad de Buenos Aires (Argentina). Investigador senior de la Vicepresidencia del Estado boliviano para el Proceso Constituyente Boliviano (2006-2009). Asesor del Defensor del Pueblo para el proceso constituyente boliviano (2006-2009). Coordinador del Proyecto Enciclopedia Jurídico Constitucional y del Centro de Estudios Constitucionales de la UCB (2011-2013). Actualmente es Ministro de Primera en la Embajada de Bolivia ante el Reino de los Países Bajos en La Haya - Holanda.

faritrojas@yahoo.com 
Simposio: Reforma Constitucional y Derechos Humanos

En los últimos años, Chile ha sido testigo de la creciente demanda de la ciudadanía por más espacios de participación, lo que se ha caracterizado por la proliferación de manifestaciones sociales y por el cuestionamiento al actual modelo de Estado. En el simposio del Anuario de Derechos Humanos del año 2012 titulado "Participación Política en Latinoamérica", se dio cuenta de este fenómeno, resaltándose que en Chile la falta de participación ciudadana en los espacios de decisión había dado paso a diversas demandas, entre ellas, la necesidad de una nueva Constitución que respondiera a las necesidades actuales de la sociedad chilena. En este contexto, actualmente uno de los temas que se encuentra en el centro del debate político y académico nacional, es la discusión constitucional. Respecto de la actual Constitución, los cuestionamientos apuntan a su falta de legitimidad democrática, los déficits de sus mecanismos de garantía de derechos fundamentales y los pocos espacios de participación ciudadana.

En ese sentido, el debate se ha orientado a determinar los mecanismos a través de los cuales se debe reformar la Constitución Política, así como a encontrar fórmulas para incorporar demandas y temáticas que han estado excluidas u olvidadas en la discusión constitucional, como son la realidad multicultural del país o la posibilidad de ampliar el catálogo de derechos protegidos y sus mecanismos de garantía. En este proceso, el Derecho Internacional de los Derechos Humanos (DIDH), pasa a cumplir un rol relevante, toda vez que en el estado actual de la relación entre el DIDH y el derecho interno, la recepción de los instrumentos de derechos humanos no solo ha sido formal, sino también sustantiva, lo que ha significado la apertura de los ordenamientos jurídicos nacionales a espacios más amplios de protección de derechos y, que el sistema internacional se ha transformado en fuente de inspiración de numerosas reformas constitucionales.

Para comprender cuál es el rol que los derechos humanos cumplen o deben cumplir en una futura reforma constitucional, hemos invitado a diversos/as juristas de la región, con el objeto de aclarar algunos conceptos y establecer algunas posiciones respecto a este tema, considerando especialmente la visión que puedan otorgarnos a partir de la experiencia comparada de procesos de reforma constitucional en países como Bolivia, México y Colombia. En este contexto, sometemos las siguientes preguntas a discusión:

1. DIDH y derecho interno. El constitucionalismo contemporáneo se ha caracterizado por avanzar hacia una cada vez mayor interacción entre el DIDH y el derecho interno. A partir de esta relación, uno de los tópicos que siempre ha permanecido vigente, es el del rol que cumplen los derechos humanos establecidos en los tratados internacionales respecto de la Constitución Política. En este debate, ¿cuál cree usted que debiera ser la jerarquía de los tratados sobre derechos humanos en la Constitución?

2. DESC. Una de las principales características de la Constitución chilena, es la escasa regulación y garantía de los derechos económicos, sociales y culturales. En los diversos procesos de reforma constitucional, se ha evidenciado que este es un ámbito problemático a la hora de llegar a consensos. A su juicio, ¿cuál es la posición y valor jurídico que una Constitución debiera darle a estos derechos?

3. Mecanismos de garantía. Uno de los aspectos que se encuentra presente en la mayoría de las constituciones, es la previsión de un modelo de protección o garantía de los derechos fundamentales. En este diseño, ¿quién cree usted que debe ser el garante de estos derechos? (tribunal constitucional, cortes superiores, todos los tribunales) y ¿a través de qué procedimientos esto se debiera hacer operativo? (acciones de tutela, hábeas corpus o mecanismos especiales en función de los derechos o titulares afectados).

4. Grupos vulnerables. La construcción tradicional del modelo de Estado en Chile en la Constitución, no ha reconocido la realidad de personas que se encuentran en situación especial de vulnerabilidad o exclusión en razón de su sexo, etnia, origen nacional, etc. ¿cree usted que es 
necesario que la Constitución regule de manera especial estas situaciones?, y si es así, ¿a través de qué vías o mecanismos?

\section{DIDH y derecho interno}

El constitucionalismo contemporáneo se ha caracterizado por avanzar hacia una cada vez mayor interacción entre el DIDH y el derecho interno. A partir de esta relación, uno de los tópicos que siempre ha permanecido vigente, es el del rol que cumplen los derechos humanos establecidos en los tratados internacionales respecto de la Constitución Política. En este debate, ¿cuál cree usted que debiera ser la jerarquía de los tratados sobre derechos humanos en la Constitución?

1. DIDH y derecho interno

\section{LILIANA GALDÁMEZ}

Definir la relación entre el derecho internacional y el derecho interno es una de las cuestiones de más difícil solución en el ordenamiento jurídico chileno; largos han sido los debates en la doctrina y la jurisprudencia sobre este asunto. Es interesante ver cómo la polémica sobre el valor del derecho internacional en el ordenamiento interno se ha centrado en el cuestionamiento al desplazamiento del poder, que se produciría en dos sentidos ${ }^{1}$. En primer lugar, porque ante la ambigüedad del artículo 5 de la Constitución, han sido los jueces y no el constituyente, quienes han resuelto por vía interpretativa la posición de los tratados y también, porque a partir del reconocimiento de la fuerza normativa del derecho internacional se produciría un segundo desplazamiento del poder, desde el ordenamiento nacional hacia el internacional. Subyace en esta última crítica la convicción de que el derecho internacional carece de los estándares de legitimidad que posee por definición el legislador y/o el constituyente (democrático) ${ }^{2}$. En mi opinión, la primera crítica puede ser plausible, dado que a partir de una norma ambigua (inciso segundo del artículo 5), los jueces han definido esta relación con vaivenes y poca sintonía entre la jurisdicción constitucional y la ordinaria. Sin embargo, la segunda crítica se enmarca en una comprensión aislacionista del derecho, lejana a los tiempos de globalización, universalización e integración, procesos que definen el derecho público en el siglo XXI.

Más que un problema de jerarquía, el asunto se resuelve de mejor manera desde la perspectiva de la eficacia y fuerza normativa de los tratados internacionales ratificados en el ordenamiento interno. Una solución al problema del valor de los tratados internacionales desde su jerarquía puede llevar a soluciones que no garantizan dicha eficacia. Seguir, por ejemplo, la tesis que se contiene en la Constitución Argentina, que constitucionaliza originalmente diez tratados sobre derechos humanos, no es garantía de su eficacia y, por el contrario, puede derivar en discusiones de difícil solución, como por ejemplo definir si todos o algunos tratados deben tener jerarquía constitucional.

En este sentido, una relación que se construya sobre la base de los tratados ratificados y vigentes como un canon de interpretación e integración de los derechos contenidos en la Constitución; puede ser una solución adecuada al ordenamiento chileno. Esto significa que los derechos deben ser interpretados, completados o definido su contenido y alcance, teniendo a la vista dichos tratados. Es una fórmula adecuada para dar cumplimiento a los compromisos internacionales

ZAGREBELSKY, Gustavo. "El juez constitucional en el siglo XXI". Revista Iberoamericana de Derecho Procesal Constitucional, No. 10, 2008, pp.249-268.

Una posición clásica de esta crítica es la de Jeremy Bentham, en BENTHAM, Jeremy. "Anarchicall Fallacies being and examination of the Declarations of Rights issued during the French Revolution". En: BOWRING, John (Ed.). The Works of Jeremy Bentham, Vol. 2. Edimburgo: William Tait, 1843. Citado por: PÉREZ LUÑO, Antonio. Derechos humanos, Estado de Derecho y Constitución. Madrid: Tecnos, 1984, p.26. 
Simposio: Reforma Constitucional y Derechos Humanos

adquiridos y por asumir. Esta solución supone que para efectos de interpretar las cláusulas de los tratados, habrá que recurrir a las opiniones de sus órganos e impone a los jueces el deber de completar la interpretación de los derechos, considerando también su desarrollo en el derecho internacional.

Una referencia especial merece el ius cogens internacional, cuya fuerza normativa ha sido reconocida por la jurisdicción ordinaria ${ }^{3}$. En este sentido, parece oportuno introducir una norma para reconocer su valor y supremacía en el ordenamiento nacional.

En conclusión, al menos dos normas sobre este asunto requiere la Constitución. Una que reconozca el valor de los tratados internacionales como un canon de interpretación e integración, y otra para garantizar la supremacía de las normas del ius cogens.

\section{PEDRO SALAZAR}

1. DIDH y derecho interno

Me parece que es importante precisar que existe una diferencia entre hablar de los tratados sobre derechos humanos y las normas de derechos humanos contenidas en tratados internacionales. Desde mi perspectiva, lo importante es identificar cuál es la jerarquía de estas normas -independientemente de cuál sea la naturaleza del tratado en el que se encuentren- al interior de los ordenamientos nacionales. Dada la materia contenida en las mismas me parece que su jerarquía debe ser constitucional. Ello más desde una perspectiva material que desde un punto de vista formal. Esto supone que deben servir como parámetro de validez de las decisiones políticas y al mismo tiempo, como criterio de interpretación. En este sentido, la jerarquía normativa ahora debe seguir una lógica de contenidos.

Vale la pena recordar que en el nivel constitucional deben incluirse todas aquellas normas y principios que otorgan identidad a un ordenamiento constitucional determinado. Por lo mismo, si se aspira a constituir una democracia constitucional, los derechos humanos deben formar parte de esa base constituyente. Esto no significa que la Constitución deba contener solamente normas de principios e incorporar derechos humanos, ya que la dimensión orgánica (el "cuarto de máquinas de la constitución" como señala Gargarella ${ }^{4}$ ) es muy relevante; pero sí implica que los derechos humanos -contenidos en una suerte de "Ius Costitutionale Commune" de fuente internacional- deben considerarse como parte de la Constitución.

Todo lo anterior no supone que los ordenamientos nacionales pierdan identidad. Cada Estado puede configurar su identidad constitucional incorporando principios constitucionales propios -por ejemplo, el federalismo o la laicidad- y que no necesariamente deben estar presentes en otros ordenamientos, lo que tendrá algunos efectos en materia de derechos humanos. Siempre que estos principios sean compatibles con el constitucionalismo democrático, será legítimo que a partir de los mismos, se configuren esquemas de limitaciones, restricciones, regulaciones, etcétera, para el ejercicio de algunos derechos constitucionales/convencionales.

Reconocen la fuerza vinculante de las normas del ius cogens internacional, entre otras, las siguientes resoluciones: Corte Suprema: sentencia de 13 de marzo de 2007. Rol 3125-2004. En el mismo sentido: Corte Suprema. Sentencia de 9 de septiembre de 1998. Rol 469-1998; sentencia de 28 de julio de 2004. Rol 5169-2004; sentencia de 17 de noviembre de 2004. Rol 517-2004; sentencia de 13 de diciembre de 2006. Rol 559-2004; sentencia de 27 de junio de 2007. Rol 45-2006; sentencia de 13 de noviembre de 2007. Rol 6188-2006; Corte de Apelaciones de Santiago: sentencia de 13 de noviembre de 2007. Rol 13.447-2006; sentencia de 18 de diciembre de 2007. Rol 1579-2007; sentencia de 27 de julio de 2007. Rol 3806-2006; sentencia de 16 de agosto de 2007. Rol 7668-2006 y; sentencia de 18 de diciembre de 2007. Rol 11801-2006.

4 GARGARELLA, Roberto. "El constitucionalismo latinoamericano y la sala de máquinas de la Constitución (19802010)". Gaceta Constitucional, No. 48. Disponible [en línea] <http://www.gacetaconstitucional.com.pe/sumario-cons/doc-sum/GC\%2048\%20Roberto\%20GARGARELLA.pdf> [consulta: 27 de marzo de 2014]. 
1. DIDH y derecho interno

\section{HUMBERTO SIERRA}

Un primer acercamiento a la respuesta se encuentra en la importancia de los derechos humanos, su contenido esencial inherente a los seres humanos, su indivisibilidad e interdependencia y su universalidad (aunque sin perder de vista las complejidades de este término), que sugieren una jerarquía superior frente a los ordenamientos jurídicos de los Estados. En efecto, no hay lugar a dudas -en el escenario actual del Derecho Internacional- que las normas en materia de derechos humanos, cuando no están inmersas en tratados internacionales, están dotadas de esa opinio iuris, y esa práctica reiterada que convierte tales preceptos en obligaciones a cargo de todos como verdadera costumbre internacional. Ello, cuando no han sido identificadas por la jurisprudencia de las Cortes como normas imperativas o de ius cogens.

Ahora bien, teniendo en cuenta su obligatoriedad para todos los Estados, ello supone el deber a cargo los Estados de acomodar sus ordenamientos jurídicos a tales predicamentos sin excepción alguna, por lo que -en otras palabras-, los derechos humanos se constituyen en cánones de obligatorio acatamiento que subordinan a los ordenamientos jurídicos internos ${ }^{5}$.

Pero lo que no hace la sociedad internacional al establecer estas reglas de juego es indicar cómo se debe hacer efectivo este mandato; si bien el Derecho Internacional indica que los Estados "[...] no podrá[n] invocar las disposiciones de su derecho interno como justificación del incumplimiento de un tratado" ${ }^{\prime \prime}$, no establece el modo en que tales obligaciones deben hacerse efectivas en esos ordenamientos jurídicos. Por tanto, el modo de materializar la superioridad de los derechos humanos en los ordenamientos jurídicos es una cuestión que queda sometida a la soberanía de los Estados.

En este sentido, surge una nueva interrogante, referida a cómo establecer dentro del orden interno de un Estado esa superioridad normativa de los derechos humanos.

En la actualidad, esta cuestión es solucionada en las constituciones por medio de las denominadas "cláusulas de recepción" o "cláusulas de remisión", mediante las cuales se introducen en la carta política ciertos puentes de comunicación directa con el DIDH, solucionando cualquier conflicto que pueda surgir al respecto.

En la Constitución Política de Colombia se pueden apreciar este tipo de cláusulas en el artículo 93, que expresamente establece la prevalencia en el orden interno de los "tratados y convenios internacionales ratificados por el Congreso, que reconocen los derechos humanos y que prohíben su limitación en los estados de excepción"; en el artículo 53 que establece que "los convenios internacionales de trabajo debidamente ratificados, hacen parte de la legislación interna"; en el artículo 101, que en materia de definición de límites remite a lo establecido al respecto en los tratados internacionales ratificados por Colombia; y en el artículo 214, que en materia de Estados de excepción establece como uno de los límites al poder ejecutivo "las reglas del Derecho Internacional Humanitario".

Por otro lado, en este mismo ordenamiento jurídico, la Corte Constitucional colombiana ha sido un garante de la aplicación de este concepto de supremacía de los tratados internacionales en materia de derechos humanos. En efecto, como supremo tribunal de la jurisdicción constitucional, a quien se le encargó la guarda y el respeto de la Carta Política, por medio de su jurispru-

La jurisprudencia internacional ha sido enfática al establecer la subordinación del derecho interno al derecho internacional. Un estudio de estas resoluciones en: BROTÓNS, Antonio. Derecho Internacional, Curso General. Valencia: Tirant lo Blanch, 2010, p.396.

Artículo 27 Convención de Viena sobre Derecho de los Tratados de 1969. 
Simposio: Reforma Constitucional y Derechos Humanos

dencia ha construido el concepto de "Bloque de Constitucionalidad", sobre la base del citado artículo 93.

Esta figura fue por primera vez considerada en la sentencia C-225 de $1995^{7}$, ante la pregunta acerca del alcance de la prevalencia en Colombia de los convenios de Derecho Internacional Humanitario y, desde ese momento, no ha cesado esta Corte en su aplicación.

Con base en esta herramienta jurisprudencial, la Corte Constitucional ha logrado integrar una gran barrera de protección de los derechos humanos con aplicación directa del Derecho Internacional en el ordenamiento jurídico interno, lo cual, desde luego, le ha permitido al Estado colombiano (por lo menos en este escenario judicial), ser un garante de las obligaciones internacionales en materia de derechos humanos.

En síntesis, en la actualidad la superioridad de los derechos humanos en la jerarquía normativa es indiscutible, en la medida en que tienen unas características especiales que los hacen obligatorios para toda la comunidad internacional. Ahora bien, para hacerlos efectivos dentro del ordenamiento jurídico, si bien los Estados son autónomos en el modo en el cual hacen aplicables estos preceptos, deben ubicarlos en el máximo rango normativo, para que efectivamente puedan cumplir con las obligaciones internacionales asumidas al respecto.

\section{FARIT ROJAS}

1. DIDH y derecho interno

Considero que los tratados sobre derechos humanos deben poseer una jerarquía supraconstitucional, sin importar si el tratado haya sido solo suscrito, ratificado o si simplemente el Estado se hubiera adherido a éste. En efecto, esta jerarquía se corresponde con la discursividad dominante o lo que Richard Rorty ha denominado como "consenso de auditorio", propio del neoconstitucionalismo, postpositivismo, garantismo u otro nombre de modernidad jurídica racional. Esta discursividad dominante se refleja en los sistemas regionales y universales de derechos humanos. Pese a que es clara mi posición respecto al carácter universal de los derechos humanos -no los considero universales-, lo cierto es que aspiran a la universalidad.

Por otra parte, creo que la forma en que se ha construido la noción de Bloque de Constitucionalidad, en la que los instrumentos internacionales sobre derechos humanos (y allí se pueden encontrar no solo los tratados), se aplican de manera preferente si es que consagran derechos más favorables, da la posibilidad de aplicar -en determinados casos- de manera preferente la normativa internacional si esta es más favorable a la protección del ser humano concreto, es decir, del ser humano particular, en su situación específica. Estas consideraciones están recogidas expresamente en la Constitución de Bolivia en los artículos 256 y 410, así como en los archivos del proceso constituyente.

En este sentido, en Bolivia los instrumentos internacionales sobre derechos humanos son parte del Bloque de Constitucionalidad, es decir, no se encuentran por sobre la Constitución, ni por debajo, sino que son parte de la Constitución, y en caso de conflicto entre normas nacionales e internacionales, se aplica la norma más preferente a la protección de la persona humana.

Para explicar porqué la Asamblea Constituyente en Bolivia determinó estas nociones de supremacía de los tratados e instrumentos internacionales en materia de derechos humanos, debe recordarse que, como otras asambleas, esta estuvo conformada por comisiones y una de ellas

Corte Constitucional de Colombia. Sentencia de 18 de mayo de 1995. C-225/1995. M.P. Alejandro Martínez Caballero. Revisión constitucional del "Protocolo adicional a los Convenios de Ginebra del 12 de agosto de 1949, relativo a la protección de las víctimas de los conflictos armados sin carácter internacional (Protocolo II)". 
se denominó "Comisión de derechos, deberes y garantías". Los miembros de esta comisión tenían una experiencia previa como activistas de derechos humanos en Bolivia y eran interlocutores del discurso dominante sobre los derechos humanos, denominado como "garantismo", "neoconstitucionalismo" o corrientes del "Estado de derecho virtual", etc. En consecuencia, en la redacción de los proyectos de borrador del apartado sobre derechos, deberes y garantías, es clara la manera en la que esta discursividad se ve expresada.

\section{DESC}

Una de las principales características de la Constitución chilena, es la escasa regulación y garantía de los derechos económicos, sociales y culturales. En los diversos procesos de reforma constitucional, se ha evidenciado que este es un ámbito problemático a la hora de llegar a consensos. A su juicio, ¿cuál es la posición y valor jurídico que una constitución debiera darle a estos derechos?

2. DESC

\section{LILIANA GALDÁMEZ}

El reconocimiento y tutela de los DESC es lo que puede definir la transformación del modelo de Estado instalado en la Constitución de 1980. Se trata de una cuestión sumamente sensible para el debate democrático. Si bien todos los derechos tienen costo $^{8}$, en Chile y desde el retorno a la democracia, los DESC han tenido más desarrollo por vía legislativa que constitucional. Esto implica que su ámbito de garantía puede cambiar y no porque estos derechos puedan ser ampliados, sino porque también pueden ser limitados. La tutela constitucional del derecho a la salud y la educación, está hoy en el centro de las expectativas de los ciudadanos para los próximos años.

En relación a los DESC, Humberto Nogueira señala que "en la nueva perspectiva del Estado Social, se asume la necesidad de brindar a la población un mínimo básico de bienestar que se compromete a entregar el Estado a través de prestaciones positivas de hacer respecto de las personas en salud, educación, condiciones laborales, seguridad social, vivienda, entre otras materias" ${ }^{\prime \prime}$.

En este sentido, el cuestionamiento es sobre cómo y hasta dónde garantizar los DESC. Si bien, como hemos señalado, todos los derechos "cuestan", los DESC representan para el Estado un esfuerzo económico adicional al que supone la protección de derechos clásicos como la propiedad. Por ello, el reconocimiento y tutela del derecho a la salud, educación y seguridad social debe ir necesariamente acompañado de financiamiento. Garantizar y reconocer los DESC exige que el Estado asegure un mínimo universal de calidad. Requiere un compromiso de no regresión $^{10}$ y de progresividad ${ }^{11}$.

El alcance de esta protección debe ser definido por las fuerzas democráticas y el hasta donde garantizarlos requiere de una valoración de las capacidades y necesidades de financiamiento

HOLMES, Stephen y SUNSTEIN, Cass. El costo de los derechos. Por qué la libertad depende de los impuestos. Buenos Aires: Siglo 21 Editores, 2011.

9 NOGUEIRA, Humberto. Derechos fundamentales y garantías constitucionales. Vol. 3. Santiago: Librotecnia, 2009, p.10.

10 El principio de no regresión está consagrado en los artículos 4 y 5 No. 2 del Pacto de Derechos Económicos, Sociales y Culturales.

11 NIKKEN, Pedro. La Protección Internacional de los Derechos Humanos, su desarrollo progresivo. Madrid: Editorial Civitas, S.A, 1987. Además se debe considerar el compromiso que contiene el artículo 26 de la Convención Americana sobre Derechos Humanos y el artículo 2 del Pacto Internacional de Derechos Económicos Sociales y Culturales. 
Simposio: Reforma Constitucional y Derechos Humanos

que sean sostenibles.

Desde la perspectiva de Douglas North, autor de la tesis del neoinstitucionalismo, se debe "atribuir un papel mucho más fundamental a las instituciones, son el determinante subyacente del desempeño de las economías.

Si queremos construir una teoría dinámica del cambio -algo que falta en la corriente principal de la economía y que fue tratado muy imperfectamente en la teoría marxista-, debe edificarse un modelo de cambio institucional"12. Según su tesis, el pasado importa, por tanto, una reforma que consagre el Estado de bienestar en Chile, debe superar los problemas institucionales que años de neoliberalismo han instalado en las instituciones, con un funcionamiento inspirado en el rol subsidiario del Estado. Desmantelar ese funcionamiento es un gran desafío.

La tutela de los DESC requiere del consenso democrático. El Estado de bienestar no puede ser impuesto, no se logrará sin consenso.

\section{PEDRO SALAZAR}

2. DESC

Desde mi perspectiva -siguiendo la lógica de la indivisibilidad y la interdependencia entre los derechos humanos-, estos derechos deben tener pleno reconocimiento constitucional y contar con un amplio esquema de garantías constitucionales e institucionales. Ello supone abandonar la tesis de que se trata de derechos programáticos y asumir que deben ser derechos garantizables. Detrás de esta idea descansa la tesis teórica de las precondiciones de los derechos fundamentales, y que supone que el ejercicio de las libertades y de los derechos políticos exige de la garantía efectiva de algunos derechos sociales.

Es importante advertir que esta posición descarta la idea de que los derechos de libertad son derechos garantizables mediante simples omisiones a cargo del Estado (y que, por lo mismo, no son económicamente costosos), mientras que los derechos sociales son los únicos derechos que demandan acciones positivas por parte del Estado (y por lo mismo son onerosos). En realidad, como han sostenido diversos autores dedicados al tema ${ }^{13}$, todos los derechos demandan acciones positivas a cargo de las autoridades estatales $y$, en esa medida, todos exigen erogaciones de recursos públicos para ser efectivamente garantizados. En esta materia, lo que importa es garantizar los principios de progresividad, no regresividad y el empleo de los máximos recursos disponibles.

Cabe advertir que en este asunto existe una tendencia garantista en el ámbito del Sistema Interamericano de los Derechos Humanos (SIDH). A partir del reconocimiento de la relevancia que tienen estos derechos como precondición para el ejercicio de los demás - en particular en una región como Latinoamérica - se ha celebrado el protocolo de San Salvador (1988) que versa, precisamente, sobre estos derechos y la importancia de sus garantías.

\section{HUMBERTO SIERRA}

2. DESC

Del 14 al 25 de junio de 1993 se celebró la Conferencia Mundial de Derechos Humanos en Viena, en el cual se reunieron representantes de 171 Estados que adoptaron la "Declaración y Programa de Acción de Viena". El punto quinto de este

12 NORTH, Douglas. Instituciones, cambio institucional y desarrollo económico. México: Fondo de Cultura Económica, 1993, p.139.

13 Ver en particular ABRAMOVICH, Víctor y COURTIS, Christian. Los derechos sociales como derechos exigibles. Madrid: Trotta, 2003 y PARRA, Óscar. Justiciabilidad de los derechos económicos, sociales y culturales ante el Sistema Interamericano. México: CNDH, 2011. 
programa reconoció que todos los derechos humanos son universales, indivisibles e interdependientes y están relacionados entre sî́14.

Esta mención está en completa coherencia con la Declaración Universal de los Derechos Humanos de 1948, que consagra un catálogo de derechos que no hace ningún tipo de distinción entre estos, considerándolos a todos partes de una unidad. Así, encontramos el derecho a la vida, a la libertad de expresión, al debido proceso penal, a la asociación, pero también el derecho a la seguridad social (artículo 22), al trabajo (artículo 23), a un nivel de vida adecuado (artículo 25), a la educación (artículo 26), a tomar parte libremente en la vida cultural (artículo 27), entre otros.

De la misma forma, la Declaración Americana de los Derechos y Deberes del Hombre de 1948, reconoce el derecho a la vida, a la libertad de conciencia, a la protección de su honra, a la inviolabilidad del domicilio y de la correspondencia, pero también el derecho a la salud (artículo XI), el derecho a la educación (artículo XII), a participar en la vida cultural de la comunidad (artículo $\mathrm{XV}$ ), al trabajo en condiciones dignas (artículo XIV), entre otros.

Adicionalmente, ambos Pactos Internacionales de Derechos Civiles y Políticos, y Económicos, Sociales y Culturales de 1966; establecen expresamente en sus preámbulos que "[...] con arreglo a la Declaración Universal de Derechos Humanos, no puede realizarse el ideal del ser humano libre, liberado del temor y de la miseria, a menos que se creen condiciones que permitan a cada persona gozar de sus derechos económicos, sociales y culturales, tanto como de sus derechos civiles y políticos $[\ldots]^{\prime \prime}$.

Es evidente en los textos citados que no existe una división de los derechos humanos, en civiles y políticos por un lado y económicos, sociales y culturales por el otro; esto solo fue una de las tantas amargas consecuencias de la guerra fría que, actualmente, se puede tener como superada.

Si bien la idea de las generaciones de los derechos humanos prestó alguna utilidad a la doctrina constitucional como método para abordar este tema, hoy en día se revela como una separación absolutamente ficticia, que no solo va en contra de las características mismas de los derechos humanos mencionadas en la Conferencia de Viena y que se aprecian en los tratados citados anteriormente (la indivisibilidad e interdependencia), sino que además, consiente las relaciones de poder que le dieron la victoria a los fuertes frente a los débiles en la historia de la positivización de los derechos humanos y oculta esa miseria y sufrimiento de la sociedad en general, que ya en tiempos de la Declaración Francesa de 1789, clamaba por la satisfacción de unas necesidades básicas que solo mucho después fueron conseguidas por la fuerza ${ }^{15}$, sobre todo después de la llamada "primavera europea" o revolución de 1848.

Desde luego que en materia del contenido prestacional que supuestamente encarnan unos derechos y la abstención que generan otros, ya la doctrina ha avanzado a pasos agigantados en la demostración de que ambos tipos de derechos, tanto las denominadas "libertades negativas" como los "derechos de garantía", generan obligaciones de hacer y de no hacer, por lo que, en el fondo, lo que existe es una decisión o elección política de las sociedades que prefieren la materialización de unos o de otros ${ }^{16}$. Basta analizar los distintos rubros de los presupuestos de nues-

14 ONU. Conferencia Mundial de Derechos Humanos: Declaración y Programa de Acción de Viena, A/CONF.157/23, 12 de julio de 1993, punto 5.

15 Claro ejemplo de esto es la "conspiración de los iguales", liderada por Gracchus Babeuf y Sylvain Maréchal en la época de la revolución francesa, que con el "Manifiesto de los iguales" pretendían cambiar las instituciones económicas y políticas a favor de las clases más necesitadas víctimas de la revolución industrial. La conspiración fue traicionada y todos fueron arrestados, condenados y ejecutados en 1796.

16 En lengua española, ver el estudio de ABRAMOVICH, Víctor y COURTIS, Christian. Los derechos sociales... op.cit.; 
Simposio: Reforma Constitucional y Derechos Humanos

tros Estados latinoamericanos para darse cuenta de ello; el dinero que se invierte en garantizar la seguridad nacional en países como Colombia, no se compadece del presupuesto afectado a la educación; o el presupuesto que genera la administración de justicia o la garantía del debido proceso, es absolutamente mayor a aquel invertido en salud.

En este sentido, los derechos humanos no pueden ser abordados en la actualidad con la división acuñada en un mundo en constante tensión por la guerra fría. Así como lo establecen ambos preámbulos de los Pactos Internacionales, todos los derechos humanos deben ser respetados y garantizados en orden de materializar la dignidad humana y, por tanto, todos deben tener el mismo valor.

Ahora bien, la pregunta que surge de esta premisa es: cómo garantizar las obligaciones de alto contenido prestacional que surgen de todos los derechos humanos concebidos de esa forma.

Al respecto, los mecanismos de protección de los derechos, como la acción de amparo o de tutela, deben tener la delimitación suficiente dentro de los ordenamientos jurídicos de cada país, para resguardar ese mecanismo excepcional solo para los casos en donde sea urgente la protección inmediata del Estado para evitar perjuicios irremediables a las personas.

En el caso de Colombia, por ejemplo, la Corte Constitucional considera la acción de tutela un mecanismo judicial efectivo para solicitar la protección de todos los derechos reconocidos en la Constitución, los cuales se tienen como fundamentales, pero en aquellos casos en los que están en juego erogaciones presupuestales o en general, el compromiso del erario público, se exigen unos requisitos especiales, tales como: la afectación directa de la dignidad humana, que el titular del derecho se encuentre en una situación de vulnerabilidad o que exista la incapacidad económica del titular para asumir la satisfacción del derecho por sí mismo, entre otros ${ }^{17}$.

\section{FARIT ROJAS}

2. DESC

Una Constitución debería consagrar todos los derechos con un mismo valor, sin distinciones que supongan jerarquía o superioridad. En este sentido, todos los derechos deberían ser igualmente exigibles. El conflicto que traen consigo los DESC, radica en que son derechos de prestación positiva, es decir, deben ser programados para su cumplimiento por el Estado o por un tercero Ilamado a garantizar el derecho. En este sentido, los tribunales están Ilamados a hacer exigible el núcleo del derecho, lo que supone garantizar un mínimo razonable atendiendo a la particularidad del caso concreto. En este sentido, se puede establecer como un criterio de interpretación la interdependencia de los derechos humanos y la progresividad.

En la Constitución de Bolivia, todos los derechos tienen igual valor en conformidad a su artículo $13^{18}$. Todos los derechos son inmediatamente exigibles, como establece el artículo $109^{19}$, y se caracterizan por ser inviolables, universales, interdependientes, indivisibles y progresivos.

pero también encontramos en lengua inglesa: ASBJORN, Eide. Economic, social and cultural rights: a text book. Minnesota: M. Nijhoff Publishers, 1995; TUSHNET, Mark. Weak Courts Strong Rights. New Jersey: Princeton University Press, 2008, entre otros.

17 Corte Constitucional de Colombia. Sentencia de 22 de enero de 2007. T-016/2007. 
La Constitución boliviana, como otras constituciones, funciona como un conjunto de ideas rectoras (en el sentido kantiano del término) y permiten en lo posible hacer realizables los derechos. Si bien en materia de DESC no se percibe un cambio en la judicatura que garantice estos derechos, las herramientas están dadas en la Constitución y considero que en un futuro próximo están sentadas las bases para una exigibilidad social de cumplimiento de estos derechos.

\section{Mecanismos de garantía}

Uno de los aspectos que se encuentra presente en la mayoría de las Constituciones, es la previsión de un modelo de protección o garantía de los derechos fundamentales. En este diseño, ¿quién cree usted que debe ser el garante de estos derechos? (tribunal constitucional, cortes superiores, todos los tribunales) y ¿a través de qué procedimientos esto se debiera hacer operativo? (acciones de tutela, hábeas corpus o mecanismos especiales en función de los derechos o titulares afectados).

3. Mecanismos de garantía

\section{LILIANA GALDÁMEZ}

Parafraseando a Bobbio ${ }^{20}$ el problema de estos tiempos no es tanto el de reconocer nuevos derechos, sino el cómo poder garantizarlos. Por tanto, estamos frente a un asunto fundamental para un futuro orden democrático. Una reforma al actual recurso de protección y la creación de un mecanismo excepcional de tutela de derechos fundamentales ante el Tribunal Constitucional es la propuesta que planteo. En ambos casos debemos estar frente a acciones y no recursos, en sintonía con los artículos 8 y 25 de la Convención Americana sobre Derechos Humanos. Se trata de reforzar los mecanismos de tutela de los derechos fundamentales, para que sean concretos y no meras expectativas. El nuevo escenario favorable a una nueva Constitución permitirá el desarrollo libre de este debate. En mi opinión, la definición de los derechos tutelados depende de las posibilidades reales del Estado para poner el acento en estos derechos.

La reforma del recurso de protección es necesaria en cuanto a ampliar los derechos que tutela ${ }^{21}$, es decir, se debiera proteger el derecho a la educación, a la salud, a la seguridad social, por mencionar algunos derechos. Debe seguir siendo de competencia de la jurisdicción ordinaria, junto con el amparo, y debiera denominarse acción de tutela de derechos, más acorde con su naturaleza y finalidad.

Por otra parte, se hace necesario un mecanismo de tutela extraordinaria de derechos fundamentales de competencia del Tribunal Constitucional. La tutela extraordinaria de derechos debe tener carácter excepcional y para determinados supuestos que consideren la trascendencia del asunto, siempre vinculado a los derechos fundamentales. La experiencia comparada ${ }^{22}$ indica que uno de los efectos menos deseados de las acciones de tutela de competencia de la jurisdicción constitucional, es la saturación de los tribunales por la masiva interposición de esta clase de acciones. Por esta razón es que no se plantea ahora una modificación en la competencia de los jueces comunes en esta materia y se propone creación de un nuevo mecanismo de tutela extraordinaria.

\footnotetext{
20 BOBBIO, Norberto. El tiempo de los derechos. Madrid: Sistema, 1991.
}

21 Un actualizado estudio sobre el desarrollo del recurso de protección y su ampliación a la tutela de otros derechos en: NAVARRO, Enrique. "35 años del recurso de protección: notas sobre su alcance y regulación normativa". Revista de Estudios Constitucionales, No. 2, 2012.

22 ROMBOLI, Roberto. "La reforma del recurso de amparo ante el Tribunal Constitucional en España y la introducción de un recurso individual y directo en Italia". Redce, No. 11, 2009, pp. 319-362. 
Simposio: Reforma Constitucional y Derechos Humanos

Para la configuración de esta tutela extraordinaria, podrían incluirse los siguientes elementos: primero, que se trate de un asunto vinculado a la interpretación de la Constitución y los tratados internacionales con incidencia en los derechos fundamentales, desde una perspectiva general y más allá del caso concreto. Esta acción podría estar asociada con un litigio en la jurisdicción ordinaria pendiente de sentencia definitiva. Podrían solicitar el pronunciamiento del Tribunal Constitucional, la propia Corte o las partes. La tutela extraordinaria también debiera ser admitida en el ámbito de la discusión de proyectos de ley relativos a derechos fundamentales. La tutela extraordinaria es, por ejemplo, un mecanismo adecuado para que el Tribunal Constitucional reconozca, si cabe, la existencia de derechos implícitos en la Constitución. Por otra parte, no serían recurribles por esta vía las sentencias dictadas por la jurisdicción común, dado que esto transformaría al Tribunal Constitucional en una verdadera última instancia. La reforma que se introdujo en España en el año 2007 (Ley Orgánica No. 6/2007), al amparo constitucional, es un referente interesante para la formulación de esta tutela extraordinaria. Sin embargo, no puede dejarse de lado que uno de los principales problemas que derivan de esta clase de acciones es la sobrecarga de las jurisdicciones constitucionales. Cualquier reforma en este ámbito debe ir acompañada, además, de recursos materiales que permitan al Tribunal Constitucional seguir cumpliendo con todas sus competencias.

Añadiría, a modo de propuesta para el debate, la necesidad de reflexionar sobre si también pudieran incorporarse a nivel de las leyes otros mecanismos especiales de tutela, similares al amparo económico. Ello considerando especialmente el derecho a la salud, donde una acción sumaria y pronta asegura que el fin perseguido por el mecanismo sea un medio eficaz. Me refiero a las prestaciones médicas destinadas a garantizar la vida e integridad personal, cuando ella depende del acceso oportuno a tratamientos médicos y medicamentos.

\section{PEDRO SALAZAR}

3. Mecanismos de garantía

Creo que es importante advertir que la garantía de los derechos humanos o fundamentales trasciende al ámbito jurisdiccional. La garantía efectiva de los derechos requiere de una acción concertada a cargo de la legislatura, la administración pública y la judicatura. Ello por no mencionar a otras instancias de garantía que han surgido en diferentes países en los últimos años (ombudsman, órganos de transparencia, etcétera). Estas instancias de garantías especializadas -ya sean administrativas o no jurisdiccionales- se han convertido en instrumentos poderosos de protección de los derechos que sugiero explorar en un proceso constituyente como el que se propone. En el caso mexicano, por ejemplo, existe un Instituto Electoral encargado de la organización de las elecciones y de la salvaguarda de los derechos político-electorales (para lo que, además, existe un tribunal especializado); un Instituto Federal de Acceso a la Información y de Protección de Datos Personales; una Comisión Nacional de los Derechos Humanos y un Consejo Nacional para Prevenir la Discriminación, que tienen a su cargo fundamentalmente, la garantía específica de derechos humanos. Cabe advertir que la mayoría de estas instancias se replican en el ámbito de las 32 entidades federativas que integran a la república mexicana.

Desde esta perspectiva, es relevante advertir que las obligaciones de promover, respetar, proteger y garantizar los derechos humanos, corresponde a todas las autoridades de los Estados (Io que vale para todos los órdenes de gobierno en los Estados federales), sin excepciones. Pero la protección efectivas de los derechos demanda adicionalmente una vigilancia y participación a cargo de la sociedad civil. Sin esta corresponsabilidad entre los diferentes poderes del Estado y la sociedad civil, con toda probabilidad, existirá déficit en la tutela de los derechos. Este dato no es menor, porque la apropiación y defensa de los derechos por parte de sus titulares es un mecanismo de garantía insustituible de los mismos. 
Ahora bien, desde el punto de vista de las garantías secundarias de los derechos ${ }^{23}$, me parece que la mejor alternativa es la de contar con un Tribunal de Casación como última instancia de la justicia ordinaria y un Tribunal Constitucional especializado en la tutela constitucional. De nueva cuenta, es importante advertir que las dos instancias están orientadas hacia la protección de los derechos fundamentales, pero lo hacen de diferente manera. La función específica del Tribunal Constitucional sería el control de constitucionalidad sobre leyes y actos que ponen en riesgo la regularidad constitucional y en esa medida, constituye la última garantía del sistema, pero la judicatura ordinaria también tiene una responsabilidad directa en la protección de los derechos fundamentales. En México, por ejemplo, todos los jueces están obligados a realizar un control de convencionalidad difuso en la medida de sus competencias, con independencia de si dentro de esas competencias se cuenta con la potestad de dejar de aplicar o de expulsar normas del sistema jurídico mexicano.

\section{HUMBERTO SIERRA}

3. Mecanismos de garantía

Uno de los aspectos más trascendentales de la consagración de los derechos humanos en las Constituciones Políticas en esa primera parte denominada dogmática, es que (como su nombre lo indica) establece aquellas verdades inflexibles sobre las que se va a construir el Estado, la estructura que va a sostener y determinar el contenido de toda la Constitución y, de esta forma, de todo el ordenamiento jurídico. De esta forma, los derechos humanos permean ese segundo componente orgánico o estructural de las cartas políticas y con ello, toda producción normativa.

Este diseño permite identificar en los derechos humanos dos dimensiones, una subjetiva y una objetiva: mientras que la primera tiene como resultado el otorgamiento de un poder en cabeza del ciudadano para hacer o no hacer algo, sin que el Estado o cualquier tercero pueda obstaculizar este ejercicio, la segunda dimensión implica la concepción de los derechos humanos como principios, como mandatos de optimización dirigidos a enmarcar la actividad de todos los órganos y servidores públicos en la materialización de estos derechos.

De esta forma, las tres ramas del poder público y todo órgano independiente, directa o indirectamente, tienen la obligación de realizar sus funciones siempre en pro de la mayor efectividad de los derechos humanos consagrados en la Constitución y en este sentido, es todo el aparato estatal el que debe actuar de garante de los derechos en todo momento, lugar y tiempo. Esto tiene como consecuencia la constitucionalización de todo el derecho objetivo; la característica principal de los derechos humanos en su relación con el ordenamiento jurídico es su transversalidad, pues una vez se consagran como parte axiológica de la Constitución, estos irradian todo el orden social, político y jurídico.

Ahora bien ¿cómo opera esto en la realidad? En primer lugar, la Constitución Política encarna también la ficción del contrato social, del acuerdo que hace la sociedad para generar las condiciones necesarias para vivir en comunidad y, por tanto, la misma sociedad es la primera llamada a propender por aplicar los derechos humanos en todas sus relaciones con los coasociados, es decir, ejercer sus derechos y respetar los ajenos.

Sin embargo, es natural que existan conflictos en el ejercicio de estos derechos, en su alcance, en su interpretación y en su contenido, por lo cual es necesario fijar la autoridad independiente e imparcial capaz de asegurar el correcto entendimiento de los derechos, lugar que ocupa -en

23 FERRAJOLI, Luigi. "Garantías". Revista de la Defensa Pública del Departamento de Buenos Aires. Argentina, diciembre de 2000. Disponible [en línea] <http://www.defensapublica.org.ar/revista/2000/12/doctrina.int/nota.htm> [consulta: 27 de marzo de 2014]. 
Simposio: Reforma Constitucional y Derechos Humanos

aplicación básica de la estructura de cualquier Estado- la rama judicial. Son los jueces los Ilamados en estos casos a definir ese alcance, interpretación y contenido de los derechos humanos y, como existe la regla general de la separación de poderes, esto implica posibles aplicaciones equivocadas o contradictorias de los derechos, por lo que es necesario determinar una jerarquía judicial que encuentre en su cúspide una alta Corte o Tribunal que tenga la competencia de dirimir estos conflictos; no tiene que ser una Corte o Tribunal con el apelativo de constitucional ${ }^{24}$, pero si es necesario que tenga la idoneidad y competencia suficiente para fijar los precedentes necesarios y obligatorios que definan el norte judicial en esta crucial materia de los derechos humanos.

Lo que se quiere resaltar en este aspecto, es que esa característica abierta de los derechos humanos, esa transversalidad que tienen en relación con toda la ciencia jurídica, implica que su garantía esté supeditada en lo judicial a todos los jueces por medio de las vías ordinarias; ellos son los Ilamados a tenerlos en cuenta en la solución a cada conflicto que tengan a su cargo, sin importar su especialidad (civil, laboral, comercial, penal, etc.).

Adicionalmente, existen mecanismos excepcionales de protección de los derechos humanos, que coadyuvan con esta garantía ordinaria de los derechos que debe ofrecer todo Estado y como su nombre lo indica, apoyan en ciertas circunstancias la labor de todo el aparato estatal. Si se trata de la libertad personal, el instrumento idóneo de defensa será el hábeas corpus; si se trata de la privacidad o la información personal, el hábeas data será el Ilamado a proteger al ciudadano; si se trata de amenazas o vulneraciones inmediatas a los derechos, sin que existan otros mecanismos judiciales efectivos para su garantía, la acción de tutela o de amparo, con su flexibilidad procesal, será la respuesta eficiente que le sirva a las personas en pro de la efectividad de sus derechos y si se trata de una vulneración o amenaza a ciertos intereses o derechos que no están en cabeza de un individuo sino de una colectividad, pues, en algunas legislaciones, se contempla la acción popular.

Solamente si se respeta esta regla de distribución de competencias se logrará un correcto funcionamiento del Estado Social y de Derecho, y una debida protección de los derechos humanos. De otra forma, serán los instrumentos excepcionales mencionados los que reemplacen toda la legislación sustancial y procesal del Estado, creando la grave mora judicial o congestión en la administración de justicia.

Por otro lado, no se puede perder de vista que a la luz del SIDH, sea cual sea la forma de protección que se brinde a los derechos, se deben respetar los estándares que en esa materia se han venido fijando en la jurisprudencia de la Corte IDH, que en ese aspecto ha sido especialmente prolífera partiendo de la base del artículo 25 de la Convención Americana. En ese sentido, debe tratarse de un mecanismo judicial "sencillo y rápido", "efectivo", sin lugar a discriminación alguna, con posibilidad de interponer recursos y con la garantía del cumplimiento de la decisión que se adopte ${ }^{25}$.

En conclusión, lo que se pretende resaltar en este punto de la garantía de los derechos humanos, es que, en primer lugar, se trata de una competencia en cabeza de todos y cada uno de los integrantes de la sociedad, y en este mismo sentido, deben ser materializados por todos los

Aunque es indudable que un juez especializado pueda tener mayor autoridad por su dedicación exclusiva y su conocimiento especializado.

25 Véase, por ejemplo, Corte IDH. Caso 19 comerciantes vs. Colombia. Fondo, Reparaciones y Costas. Sentencia del 5 de julio de 2004. Serie C No. 109; caso Baena Ricardo y otros vs. Panamá. Fondo, Reparaciones y Costas. Sentencia de 2 de febrero de 2001. Serie C No. 72; caso Cinco Pensionistas vs. Perú. Fondo, Reparaciones y Costas. Sentencia de 28 de febrero de 2003. Serie C No. 98 y; caso Las Palmeras vs. Colombia. Fondo. Sentencia de 6 de diciembre de 2001. Serie C No. 90. 
servidores públicos en el ejercicio de sus funciones; sin embargo, si en este escenario nacen conflictos (como es apenas obvio), es la jerarquía judicial por las vías ordinarias y en cada una de sus especialidades, la llamada a hacer efectivos los derechos de cada persona y, solamente si existen circunstancias excepcionales en tales conflictos, bien sea porque se trata de derechos especiales o amenazas y vulneraciones graves, ahí sí deben ponerse a disposición de las personas los llamados mecanismos extraordinarios de protección del ser humano.

\section{Mecanismos de garantía}

\section{FARIT ROJAS}

Considero que todos los tribunales deben ser garantes de los derechos fundamentales. Asimismo, estimo que el Tribunal Constitucional debería, bajo un principio de restricción judicial, elegir los casos en los cuales busca marcar jurisprudencia, no debería conocer todas las acciones. Esto, pues la cantidad de acciones y de procesos que actualmente conoce es tan alto y con tan poco impacto real en la interpretación del derecho, que es posible sostener que -si se reduce la cantidad de los fallos- pueda producirse una mejora en la calidad de los fallos destinados a interpretar y reinterpretar la Constitución y las leyes, atendiendo más al caso concreto.

La acción por excelencia para la protección de los derechos fundamentales es la de tutela, también conocida como amparo constitucional. La especificidad de otras acciones debería darse solo si el procedimiento permite una tutela mucho más inmediata, como es el caso del hábeas corpus o la acción popular en Bolivia. En Bolivia se cuenta con un amparo constitucional (que protege todos los derechos establecidos en la Constitución), una acción de libertad (que corresponde a la acción de hábeas corpus en el derecho comparado, pero que en el caso de Bolivia no garantiza solo la libertad y el debido proceso, sino también la vida), una acción de protección de privacidad (hábeas data), una acción de cumplimiento (que tiene por objeto hacer cumplir al servidor público un mandato imperativo impuesto por la Constitución y las leyes) y una acción popular (que protege todos los derechos colectivos, incluidos los derechos del medio ambiente). Asimismo, se cuenta con un recurso sui generis, denominado recurso directo de nulidad, destinado a proteger la constitucionalidad y legalidad de las resoluciones de autoridades públicas.

Las nuevas acciones han sido aplicadas ya en muchos casos por la ciudadanía, sin embargo, es clara la necesidad de profundizar en su estudio y aplicación tanto por la judicatura como por los mismos abogados, en busca de optimizar sus resultados.

\section{Grupos vulnerables}

La construcción tradicional del modelo de Estado en Chile en la Constitución, no ha reconocido la realidad de personas que se encuentran en situación especial de vulnerabilidad o exclusión en razón de su sexo, etnia, origen nacional, etc. ¿Cree usted que es necesario que la Constitución regule de manera especial estas situaciones? y, si es así, ¿a través de qué vías o mecanismos?

4. Grupos vulnerables

\section{LILIANA GALDÁMEZ}

En relación a los pueblos indígenas, es fundamental introducir una norma que reconozca el carácter multicultural y multiétnico del país. Las fórmulas para dicho reconocimiento son de naturaleza diversa y con distintas consecuencias desde la perspectiva constitucional. Para los derechos de los pueblos indígenas, como para todas las materias acá analizadas, los tratados que el país ha suscrito constituyen el mínimo que debiera garantizarse en el nuevo orden constitucional.

Desde la perspectiva constitucional, y dado el carácter de las normas contenidas en la Constitu- 
Simposio: Reforma Constitucional y Derechos Humanos

ción, se trata de introducir el reconocimiento a la diversidad con fórmulas que deben ser definidas por el constituyente democrático. Dichas fórmulas tienen distintas consecuencias y matices que deben ser valorados por los actores llamados a participar en esta definición, ya que pueden abrir el camino hacia el reconocimiento de una suerte de régimen autonómico para los pueblos indígenas, con ámbitos de reconocimiento de competencias a sus órganos representativos. En este sentido, estos contenidos son los que deben surgir del consenso democrático y participativo; es difícil elaborar una propuesta sin considerar a los actores de esta discusión.

No cabe duda que si el derecho a la consulta ha sido incorporado al ordenamiento nacional con carácter autoejecutable (no obstante ello signifique en la última doctrina del Tribunal Constitucional una exhortación al legislador ${ }^{26}$ ); corresponde que el proceso de reconocimiento constitucional a los pueblos indígenas se concrete en consulta con dichos pueblos. Los contenidos y alcances del tratamiento de los pueblos indígenas en la Constitución requieren de su participación.

Respecto al reconocimiento de la vulnerabilidad, exclusión y diversidad que afecta a determinados grupos o sectores de la población, sería importante que a nivel constitucional se incluyera una cláusula general, que permita el desarrollo de políticas de acción positiva que contribuyan a la garantía del principio de igualdad y no discriminación. En este sentido, en mi opinión no se trata de incluir un reconocimiento explícito a determinadas minorías o población excluida por razones económicas, étnicas, de género, religión, discapacidad y otras, sino que se trata de incorporar una norma general que reconozca a los que sufren discriminación por la razón que sea y que permita habilitar mecanismos institucionales, normativos y jurisdiccionales que ataquen los mecanismos que permiten dicha discriminación. Se trata, por tanto, de incorporar en la Constitución una cláusula genérica que permita introducir y desarrollar toda clase de medidas de acción positiva que corrijan y reviertan esas discriminaciones. Todas ellas.

\section{Grupos vulnerables}

\section{PEDRO SALAZAR}

No tengo la menor duda de que la protección del principio de igualdad -formal y sustantiva- constituye una condición necesaria para la consolidación de las democracias constitucionales. Ello en particular en nuestras sociedades que están cruzadas por fuertes desigualdades y diversos tipos y causas de discriminaciones estructurales. De ahí que la agenda de la no discriminación -tal como ha sido desarrollada en diversos instrumentos internacionales y en la doctrina especializada ${ }^{27}$ - deba tener un lugar especial en el diseño de las constituciones de América Latina.

Ello supone reconocer las causas de las discriminaciones directas, indirectas y estructurales o sistémicas; identificar a los grupos que mayormente las padecen y sobre todo, crear los mecanismos constitucionales, legislativos y de política pública para revertir ese estado de cosas. De la respuesta adecuada a ese desafío depende en buena medida el éxito de nuestras transiciones a la democracia ahora en etapa de consolidación. Sin duda, cada país tiene una realidad distinta en esta materia, pero lo cierto es que, en general, en todos los países de la región latinoamericana existen discriminaciones históricas en contra de grupos vulnerables que, por lo mismo, demandan una protección especial. En esta materia, los diversos documentos producidos en el

26 GALDÁMEZ, Liliana. "Comentario jurisprudencial: la consulta a los pueblos indígenas en la sentencia del Tribunal Constitucional sobre Ley de Pesca Roles 2387-12-CPT y 2388-12-CPT, acumulados". Revista de Estudios Constitucionales, No. 1, 2013.

27 Diversos tratados internacionales contemplan la igualdad, por ejemplo la Convención Americana sobre Derechos Humanos (artículo 24). Por lo que respecta a la doctrina especializada, ver AÑON, María José. Igualdad, diferencias y desigualdades. México: Editorial Fontamara, 2001. 
marco del $\mathrm{SIDH}^{28}$ pueden servir como una guía y un referente para imaginar un diseño constitucional adecuado a la realidad del país y al mismo tiempo, orientado hacia la garantía efectiva del principio de igualdad.

Sobre este tema, en México se cuenta con un Consejo Nacional para Combatir y Prevenir la Discriminación (creado en 2003) que -aunque es una dependencia gubernamental adscrita al Ministerio del Interior (Secretaría de Gobernación)-, cuenta con un margen notable de autonomía. En 2014, tres años después de la reforma constitucional en materia de derechos humanos (junio de 2011), se aprobaron importantes reformas a la Ley Federal para Eliminar y Prevenir la Discriminación que potenciaron las potestades de esta autoridad de garantía.

\section{Grupos vulnerables}

\section{HUMBERTO SIERRA}

El paso de un Estado de Derecho a un Estado Social y de Derecho, está guiado principalmente por una nueva concepción del principio de igualdad. Mientras que en el primero se proclamaba la igualdad de todos los hombres frente a la ley, es decir, igualmente sometidos a ella e igual tratamiento dispensado por ella, que se denominó en la doctrina como igualdad formal; en el segundo la igualdad se reivindicó como real, es decir, como un principio que parte de la situación de desigualdad material que caracteriza nuestras sociedades, por lo cual su principal objetivo era equilibrar las cargas en la sociedad para efectivamente lograr un beneficio común y ello implicaba dar un trato igual a las personas en situación de igualdad y dar un trato desigual a aquellos que se presentaban como desiguales.

Un Estado Social y de Derecho, entonces, debía identificar aquellas personas que se encontraban en situaciones de desigualdad manifiesta o de vulnerabilidad, para actuar directamente sobre ellas por medio de la procura existencial ${ }^{29}$ o de un mínimo vital. Desde luego que este concepto no se basa únicamente en la satisfacción de servicios esenciales, sino que implica un nuevo enfoque del Estado que debe velar por lograr condiciones de equidad en la sociedad.

Este concepto de igualdad material o real, es absorbido por la mayoría de tratados internacionales en materia de derechos humanos, por lo que independientemente de la asunción del carácter "social" que adopte un Estado, al ser parte de tales tratados internacionales, se encuentra obligado al cumplimiento de este concepto de igualdad e implícitamente, por lo menos en ese aspecto, le otorga el carácter de Estado Social.

Así se puede apreciar en los dos pactos internacionales de derechos humanos que, a la hora de establecer las obligaciones que los Estados partes asumen al momento de la ratificación de esos tratados, hacen especial énfasis en que la obligación de respeto y garantía de los derechos reconocidos en cada texto, se debe cumplir sin ningún tipo de distinción por "[...] motivos de raza, color, sexo, idioma, religión, opinión política o de otra índole, origen nacional o social, posición económica, nacimiento o cualquier otra condición social"30.

28 Por ejemplo, se hace referencia a esto en: Corte IDH. Caso Atala Riffo y Niñas vs. Chile. Solicitud de Interpretación de la Sentencia de Fondo, Reparaciones y Costas. Sentencia de 21 de noviembre de 2012. Serie C No. 254. También véase GONZÁLEZ LE SAUX, Marianne y PARRA, Óscar. "Concepciones y cláusulas de igualdad en la jurisprudencia de la Corte Interamericana. A propósito del caso Apitz". Revista IIDH, No. 47, Costa Rica, 2008.

Este concepto de "procura existencial" fue acuñado por la doctrina alemana, su autor principal fue Ernest Forsthoff. Citado por GARCÍA-PELAYO, Manuel. Las transformaciones del Estado Contemporáneo. Madrid: Alianza Editorial, 1995, p. 27.

30 Artículo 2.1 Pacto Internacional de Derechos Civiles y Políticos (PIDCP), artículo 2.2 Pacto Internacional de derechos económicos, sociales y culturales (PIDESC). En el caso del PIDCP, el artículo 26 reitera esta prohibición de discriminación. 
Simposio: Reforma Constitucional y Derechos Humanos

En el mismo sentido, la Convención Americana sobre Derechos Humanos, al momento de determinar las obligaciones que asumen los Estados parte de la Convención, consagra el compromiso de respetar y garantizar el libre y pleno ejercicio a toda persona de los derechos establecidos allí, "[...] sin discriminación alguna por motivos de raza, color, sexo, idioma, religión, opiniones políticas o de cualquier otra índole, origen nacional o social, posición económica, nacimiento o cualquier otra condición social" ${ }^{31}$.

Si los Estados parte de estos tratados internacionales se obligan a reconocer y garantizar los derechos humanos en igualdad de condiciones a todas las personas sometidas a su jurisdicción, con especial mención de aquellas personas que han sido discriminadas por los denominados factores sospechosos de discriminación (color, sexo, raza, idioma, origen social, posición económica, etc.), entonces es un deber del Estado reconocer la situación de vulnerabilidad que presentan y tomar todas las medidas necesarias para materializar sus derechos.

De esta forma, respecto de la pregunta de si debe reconocerse en la Constitución Política la protección especial que se exige de aquellas personas que se encuentran en situación de vulnerabilidad, la respuesta es afirmativa, debido a que este es el modo más idóneo para lograr un efectivo reconocimiento y garantía de los derechos de aquellas personas históricamente excluidas de la sociedad. Más aún cuando de esta forma se logra irradiar todo el ordenamiento jurídico del modo en el que se explicó en la pregunta anterior, con el efecto transversal de los derechos humanos.

Ahora bien, en cuanto a la vía o mecanismo adecuado para esta configuración constitucional, se debe reconocer que existen múltiples formas para hacerlo efectivo, desde luego, solo estarán dotadas de idoneidad aquellas que lo hagan desde la parte dogmática de la Carta por los efectos ya mencionados. Con la denominación del Estado como Social y de Derecho, ya se trae al orden interno todo el concepto de igualdad material, en el sentido referido anteriormente; también puede incluirse la consagración expresa del derecho-principio a la igualdad material e incluso; se pueden incluir menciones especiales sobre aquellos titulares de derechos que encontramos directamente en situación de vulnerabilidad.

En el caso de la Constitución Colombiana, por ejemplo, encontramos las tres formas referidas de inclusión de esta cláusula de protección de las personas en situación de vulnerabilidad. En efecto, en el artículo primero se establece que Colombia es un Estado Social de Derecho, pero además en el artículo 13, se consagra una cláusula de protección especial ${ }^{32}$.

Adicionalmente, se incluyeron previsiones especiales respecto de las mujeres en estado de embarazo (artículo 43); los niños y niñas (artículo 44); los adolescentes (artículo 45); las personas en la tercera edad (artículo 46); las personas en situación de discapacidad (artículo 47); los tra-

\footnotetext{
31 Artículo 1.1 y que se reitera en el artículo 24. Respecto a la protección de las personas en situación de vulnerabilidad, la Corte IDH ha señalado: "En el marco de sus obligaciones de garantía de los derechos reconocidos en la Convención, el Estado debe abstenerse de actuar de manera tal que propicie, estimule, favorezca o profundice esa vulnerabilidad y ha de adoptar, cuando sea pertinente, medidas necesarias y razonables para prevenir o proteger los derechos de quienes se encuentren en tal situación". Corte IDH. Caso Vélez Loor vs. Panamá. Excepciones Preliminares, Fondo, Reparaciones y Costas. Sentencia de 23 de noviembre de 2010. Serie C No. 218.

32 Artículo 13. "Todas las personas nacen libres e iguales ante la ley, recibirán la misma protección y trato de las autoridades y gozarán de los mismos derechos, libertades y oportunidades sin ninguna discriminación por razones de sexo, raza, origen nacional o familiar, lengua, religión, opinión política o filosófica. El Estado promoverá las condiciones para que la igualdad sea real y efectiva y adoptará medidas en favor de grupos discriminados o marginados.El Estado protegerá especialmente a aquellas personas que por su condición económica, física o mental, se encuentren en circunstancia de debilidad manifiesta y sancionará los abusos o maltratos que contra ellas se cometan".
} 
bajadores agrarios (artículo 64); entre otras.

4. Grupos vulnerables

\section{FARIT ROJAS}

Considero que sí, es necesario que la Constitución regule de manera especial estas situaciones a través de acciones afirmativas y generando el marco general para el desarrollo de políticas públicas destinadas a garantizar el ejercicio efectivo de los derechos humanos de personas pertenecientes a grupos vulnerables.

En el caso de pueblos indígenas, considero que deben preverse no solo medidas de trato diferenciado, sino también la posibilidad de que puedan generar y recrear sus condiciones culturales, políticas, económicas y jurídicas de la vida cotidiana, lo que supone pensar en el marco jurídico adecuado para autonomías indígenas, territorialidad, pluralismo jurídico y medidas de apoyo del Estado a los autogobiernos indígenas.

En el caso boliviano, por ejemplo, se establecieron las condiciones para el desarrollo de una justicia indígena, de un autogobierno indígena y de una territorialidad e institucionalidad indígena. Sin embargo, al momento de la aplicación de estas normas, se conserva el carácter paternal propio del colonialismo, que consiste en revisar, adecuar, e incluso intervenir las decisiones adoptadas por los pueblos indígenas. 
